\title{
An Approach to Domestication and Foreignization from the Angle of Cultural Factors Translation
}

\author{
Fade Wang \\ Foreign Language College, Huaiyin Institute of Technology, 223003, Jiangsu, China
}

\begin{abstract}
The essence of translation is transferring the information expressed by one language to another. It concerns not only the transfer between languages, but also between cultures. The truth that translation is also an intercultural activity can be further proved by the relationship between language and culture. In translation field, there has long been a hot debate over the proper translation strategies chosen for the transmission of cultural contents, and foreignization and domestication have been the focus of debate since their appearance. They can be viewed as the extension of the debate on "free translation" and "literal translation". In this article, through analysis on the actual application of foreignization and domestication from the aspects of authors' translative intentions, readers' demands, cultural aura of concrete texts in novel translation, I arrived at the conclusion that the choosing of foreignization and domestication is not fixed, and the two methods should supplement and complement each other, and that in literature translation, translators should mainly adopt foreignization, and don't hesitate to choose domestication when it is necessary.
\end{abstract}

Index Terms - foreignization, domestication, culture, literal translation, free translation, intercultural communication

\section{INTRODUCTION}

In the field of translation, there has long been a point at issue over the proper translation strategies chosen for the conveyance of cultural elements. The two major ones are foreignization and domestication, which have been the crux of contention since their emergence in translation studies (Hu, Cui'e, 2000).

The essence of translation is to transfer the information represented in one language into another one. However, literary translation is not only a kind of transfer of language symbols, but also a kind of communication between cultures (Zhang, Jin, 1987). Generally speaking, literature translation is to pass on the artistic mood of a literary work with another language so as to make the readers enlightened, moved, and make them get the same feelings of beauty as if he is reading the original work. Therefore, literature translation has the same significance as literature creation. It is not simply the change from one language into another, but also the introduction of one culture into another (Zhang, Baohong, 2001). Thus, it is a creative work.

During the last few years, scholars at home and abroad have conducted a series of researches on foreignization and domestication in literature translation from other certain aspects. My paper aims to explore these two strategies in literature translation mainly from the angle of cultural elements' translation, analyze and summarize their application, mutual relationship and future development.

\section{Culture, Language and Translation}

\section{A. Culture and Language}

Narrowly speaking, culture refers to local or specific practice, beliefs or customs, which can be mostly tasted in folk culture, enterprise culture, or food culture etc.; while broadly speaking, culture means the total way of life of a people, including the patterns of belief, customs, objects, institutions, techniques, and language that are characteristic of the life of the human community (Hu, Wenzhong, 1994). In this article, culture refers to the body of customary beliefs, social forms and material traits constituting a distinct complex of tradition of a racial, religious, or social group (Merriam-Webster, 1967).

Having evolved together through the history, Language and culture are intrinsically dependent on each other. Proof on their mutual interdependence can be found in the origin of civilization, the development of writing and human communication. Much of the recent work has revealed that language is related to cognition, and cognition in turn is related to the cultural setting.

On the one hand, a language not only describes facts, ideas, or events which indicate similar world knowledge of its people, but also mirrors the people's attitudes, beliefs, world outlooks etc. In a word, language represents cultural reality. On the other hand, as people's language uses reflect the culture, to be more specific, their community culture is revealed by its social conventions, norms and social appropriateness, the culture both emancipates and constrains people 
activities socially, historically and metaphorically.

E. A. Nida, a famed American translation theorist, recognized the major elements of culture as ecological culture, material culture, social culture, and linguistic culture. All these show that language is a part of culture. Being an essential component of culture and playing a very important role in culture, language is influenced and shaped by culture; language carries culture, mirrors culture, spreads culture and helps develop culture. It is only in language that culture can be well presented and handed down from generation to generation. It is appropriate to say that language is the transmitter for culture and culture is the fertile earth from which language forms and develops. To understand a language, one must know well about its culture and vice versa. So it is quite understandable to say that learning a language is, in a way, learning the culture and customs of the country where the language is prevalent.

\section{B. The Importance of Culture in Translation}

In recent years, the translation circle has been putting more and more emphasis on cultural factors in translation. Thus, translation is not only a process of cultural transplantation, but also an activity of intercultural communication. The illustration of the relation between culture and language places us in a better position to clarify the relationship between culture and translation. Translation process involves both the transfer of language and culture. To be more exact, culture exhibits the essential activity during the process of translation. That is to say, the essence of translation is a kind of cultural activity. On the one hand, translation is a kind of cross-cultural communication. Translation, from the perspective of communication theory, is a way of conveying messages and exchanging information. More exactly, it is an intercultural communication between the author and the translator, and between the translator and the readers of the target language. On the other hand, translation is a medium of cultural exchange. The purposes and characteristics of translation lie in cultural and ideological exchanges. It is the urge of people in different communities, nationalities, regions and countries to get to understand each other that makes translation a necessity. In the translation history, materials characteristic of human wisdom and human culture became the target of translation. Since knowledge of one country is expressed to another mainly in foreign language, translation is constantly an important means of acquiring and spreading knowledge. We may even assume that most cultural systems in the world cannot have developed so far without the aid of translation.

\section{FOREIGNIZATION AND DOMESTICATION}

\section{A. Origin and Definitions}

The notion of Foreignization and domestication in translation field was first put forward by an American scholar Lawrence Venuti in his book The Translator's Invisibility in 1995, and this term came directly from an academic thesis read out by a German scholar Schleier Marcher in 1813.

Foreignization is a source-culture-oriented translation which strives to translate the source language and culture into the target one in order to keep a kind of exotic flavor (Feng, Jianwen, 1993). Schuttleworth and Cowie have defined foreignization as a term used by Venuti to represent the type of translation in which a TT is produced which deliberately depart from target conventions by keeping something of the foreignness of the original(Schuttleworth \& Cowies, 1997). While domestication refers to the translation which is oriented to the target culture and in which unusual expressions to the target culture are transmuted and changed into some familiar ones so as to make the translated text easy to be understood by the target readers. Schuttleworth and Cowie have defined domestication as a term adopted by Venuti to describe the translation strategy in which a lucid, fluent style is used in order to minimize the foreignness of the foreign text for TL readers (Schuttleworth \& Cowies, 1997).

Venuti is the representative advocate of foreignization. He openly pronounced that the aim of foreignization is to develop a kind of translation theory and practice to resist the trend of the dominance of the target language, so as to give prominence to the difference between the original and the version in terms of language and culture (Venuti, L, 1995). While Nida is the representative advocate of domestication. He puts forward the notion of the most natural equivalent. Based on the perspective of society and culture, he puts the target reader into the first place. He thinks that the rendition in the version should be completely natural, that the behavioral mode in the source language should be assimilated into the target readers' cultural sphere (Eugene A. Nida \& Charles R. Taber, 1993). And such a translational notion doesn't emphasize the concept that the target readers should accept the behavioral mode in the source language for the understanding of the source message.

\section{B. Literal Translation and Free Translation}

The controversy on foreignization and domestication can be regarded as the extension of the debate on free translation and literal translation. Literal translation concerns much about the issue of technical handling in language aspect, that is, how to keep the form of the source language without distorting its meaning. It is a translation that follows not only the content but also the form of the source language. Translators employing literal translation method have been willing to discard the formal elements of the target language and even the comprehensibility of the target language text for the sake of doing their best to keep the similarity in form of the source text. Nevertheless, literal translation is totally different from mechanical or dead translation. Free translation holds that different languages have different cultural connotations and expressing forms, and when the form hinders translation, free translation should be 
adopted. Those who prefer free translation method have been more likely to pursue elegance and intelligibility of the version at the expense of the form of the source language.

\section{The Relation between the Two Pairs of Translation Strategies and Methods}

The two pairs of translation strategies have some points in common: literal translation and foreignization lay more emphasis on the linguistic and stylistic features of the original text, and the target text translated in these ways may not be very clear and coherent in language and the content may not be easy to understand for the target readers, so they may feel a bit strange when reading the translation; while free translation and domestication care more about the target audience, and because of the smooth sentences, the familiar expressions and cultural phenomena in the version, sometimes the target readers may not be aware of the fact that they are actually reading a translated text from another culture (Ye, Zinan, 1991).

However, this does not mean the two pairs are the same. There are some disparities between them. When a translator employs either literal translation method or free translation method, he focuses his attention mainly on the linguistic factors of the original text and tries his utmost to preserve the original meaning in the target text. But with the development of the translation studies, more and more translators and theorists have realized that translation is a far more complicated activity which is related to cultural, poetic, as well as economic factors. Therefore, foreignization and domestication is a pair of new translation strategies which are more intricate and inclusive than literal and free translation methods and which are mainly concerned about cultural factors in translation.

\section{EMPLOYMENT OF FOREIGNIZATION AND DOMESTICATION IN NOVEL TRANSLATION}

\section{A. Authors'Translative Intentions}

Translators adhere to different principles according to different translative intentions. Take two English versions of Hong Lou Meng (A Dream of Red Mansions) which contains enormous cultural factors for example. Yang Xianyi and his wife Gladys Yang, generally employed foreignizing method in translating this classic Chinese novel in order to introduce Chinese culture to English readers as much as possible. They translated the title of the book as A Dream of Red Mansions which is generally regarded as the translated name of “红楼梦”.

While Hawkes, on the contrary, mainly adopted domesticating translation strategy so as to cater to the western readers' tastes and bring them the feeling of enjoyment through light and smooth reading. He translated the title of the novel as The Story of the Stone which is another name of Hong Lou Meng for the sake of avoiding "red" which is often associated with "blood and killing" in western culture. In this version, he translated "red" as "green" in many places, such as “怡红院” as “The House of Green Delight”, “怡红公子” as “Green Boy”. It is very hard to tell which version is better, since they are both successfully accepted by their readers respectively. However, personally, I prefer the version of Yang Xianyi and Gladys Yang's which is in keeping with the fashion of times, because nowadays westerners are increasingly desirous of knowing and learning more about China.

Another Example: 宝玉看了, 心下自思道: “原来如此。但不知何为 ‘古今之情”, 何为 ‘风月之债”? 从今倒要 领略领略。”宝玉只顾如此一想，不料早把些邪魔招入膏育了。(Cao, Xueqin \& Gao, E, 1987, P.34)

"Well, well," thought Pao - yu, "I wonder what's meant by 'passion from time immemorial' and 'debts of breeze and moonlight'?" Little did he know that by thinking in this way he had sum-moned an evil spirit into his inmost heart. (Yang, Xianyi \& Gladays Yang, 2010)

Based on the original work' culture, Mr. Yang and his wife translated “风月之债” as “debts of breeze and moonlight” by employing foreignizing method, without any additional explanation or annotation. Most probably, such a version will make the target language readers bewildered. Since to the source language readers, such a Chinese allusive term as “风月之债” can inevitably arouse profound fancy about the romance between two sexes, yet to ordinary target language readers, the Chinese term “风月” only means the natural phenomenon, nothing associated with the deep implication can be inferred. Therefore, for avoiding the misunderstanding of the target language readers, certain explanation or annotation is necessary. E.g., in the English version, add a annotation: “风月” means “love affair” and “风月之债” refers to "love debts".

\section{B. Readers'Demands}

Readers' demands can also greatly affect translators' translative methods when cultural communication between different countries and peoples are still at the early stages, when people are not very familiar with foreign cultures and languages, and are quite strange to large numbers of foreign notions and terms. Thus, if translators employ foreignization strategy too frequently when translating a literary work, the target-language readers may feel very strange to the translated version and may even have a misunderstanding of the source- language culture.

$\mathrm{Fu}$ Donghua, in his translation of Gone with the Wind (Mitchell, Margaret, 1979), mainly used domestication method. A case in point is that he adopted traditional Chinese family names for the naming of the leading characters in the novel. For example, he translated “Scarlett “as “郝思嘉”, and “Rhett” as “白瑞德”. In addition, he translated many place names with unique Chinese flavors. However, it doesn't mean that when translating the novel he completely abandoned foreignization, which faithfully expressed the information of the original work. Nowadays, the globalization of 
economic trade is greatly pushing forward the mutual communication and merging between different countries and peoples. As a result, ways of cultural communication between them is becoming more and more varied and people are beginning to observe and accept foreign culture with an open rather than a narrow mind. Accordingly, in literature translation, some contents that need to be domesticated in the past can be completely foreignized today, which is really quite natural with the change of our society with each passing day.

\section{Cultural Aura of Concrete Texts}

In concrete context, translators' choosing of translative methods can also be greatly affected by the content of concrete texts. Take the translation of an exclamatory sentence in Vanity Fair by Thackery for example (Thackerary, William, 2000). In its Chinese version, “God bless you!” is translated by the translator Yang Bi as “求天保佑你们!”

In western countries where Christianity is prevailing, many words and expressions for everyday use are full of religious colors of Christianity. Yang Bi adopted domesticating method which seems to make readers feel intimate when reading. However, as far as I'm concerned, it would be better to choose foreignization strategy to translate the sentence as “求上帝保佑你们!”, mainly because of two reasons: first, readers would not feel difficult in understanding the sentence with the help of "bless"; second, it would help to introduce foreign culture to Chinese readers and stimulate them to explore more related knowledge.

Next, let's look at another translation of a proverb in Hong Lou Meng (A Dream of Red Mansions).

Yang Xianyi and Gladys Yang adopted foreignizing translation to translate the proverb “谋事在人, 成事在天” as "Man proposes, Heaven disposes" (Yang, Xianyi \& Gladays Yang, 2010, P. 120) which is similar to the English idiom "Man proposes, God disposes". Obviously, through association western readers can easily understand the meaning of the proverb and know more about Chinese culture through inference.

While in some other cases, if translators adopt foreignization to deal with cultural differences, it may cause misunderstanding or barriers in understanding of source-language culture, then domestication should be used. Take the translation of one sentence in one English novel for example.

I'm a selfish pig. (我是头自私自利的猪.)

The translator adopted foreignization, which is more likely to cause misunderstanding, since in western countries, "pig" is often associated with "dirty, greedy and selfish", while in Chinese, “猪” in most cases means "stupid." Therefore, it would be better to use domestication to translate the original English sentence as “我是个自私鬼.” In this way, the sentence can present the readers with a faithful image of the character who utters such a remark in the novel.

Thus, the choosing of the two methods can't be lumped together. Translators should made proper choice according to concrete situations.

\section{AdVAntage AND Disadvantage of Foreignization AND DOMESTICATION IN APPLiCATION}

According to the above analysis, foreignization and domestication both have their advantages in literature translation with regard to different times, readers' demands, translative intentions, concrete texts and so on. And, of course, their disadvantages also can't be denied. Domestication makes readers have a taste of the similarities between different cultures, at the same time makes translated texts smooth, clear and coherent so as to accord with target-language readers' reading and expressing habits (Zhu, Jianping, 2002). However, domesticaticated translations can also blot out characteristics of nations and peoples, which therefore inevitably causes distortions of original texts.

While foreignization tries to keep an exotic atmosphere for target-language readers, and makes them feel the difference between languages and cultures. We can find many successful cases of foreignization. “Kungfu” (功夫), “erhu"(二胡), “the Great Cultural Revolution”(文化大革命)”, “jiaozi” (饺子) are successful examples of foreignization of Chinese phrases, and “时间就是金钱.”(Time is money.), “酸葡萄” (sour grapes) “象牙塔” (ivory tower), “鳄鱼的 眼泪” (crocodile's tears) are successful examples of foreignization of English phrases. It can be said that foreignization is of advantage to the communication and mergence of two different cultures and languages. However, foreignization is not always applicable because it may cause misunderstanding or barriers in understanding. For example, “红白喜事” can be best translated as "weddings and funerals" in a domestication way rather than "the red and white happy event"; while the translation of “I’m not Hamlet.” as “我不是哈姆雷特。” Sounds equivocal, and another Chinese version “我 决不优柔寡断。” is explicit and to the point. Other praiseworthy translation examples through the employment of domestication method: Justice has long arms (天网恢恢, 疏而不漏); The two friends are hand- in-glove with each other(这两位朋友情同手足); 不到黄河不死心(Refuse to give up until all hope is gone).

Many people only see the contradiction and opposition between foreignization and domestication, and put emphasis on their incompatibilities. They neglect the unity of opposition and compatibility of the two. In the process of literature translation, the choosing of the two is not fixed, and should be decided according to actual situations. The two methods should supplement and complement each other (Zhu, Jianping, 2002).

\section{CONCLUSION}

Translation is an art of choosing. In the process of literature translation, translators always face the choosing of 
strategies of foreignization and domestication. In view of the above analysis of the two methods in novel translation, it's not difficult to find that foreignization is the inevitable tendency in literature translation at the present time, since being faithful to the original works, keeping local conditions and customs of foreign countries, satisfying readers' expecting view is a must in the process of global cultural communication and mergence.

In the $21^{\text {st }}$ century, foreignization will be the keynote in literature translation. Of course, as translators stick to holding foreignization as the main translative method, the supplementary role of domestication can't be neglected. Domestication, as another important strategy for translation, can make the original more intimate to readers and make up the inconvenience caused by too many difficult unfamiliar cultural factors in the original. Thus, domestication can better pass on the spirits of original works when foreignization is awkward in fluently expressing the contents of literary works. Therefore, translators should adopt foreignization as far as possible, and don't hesitate to use domestication when it is necessary. Only when translators properly choose foreignization and domestication and combine them appropriately, can they bring satisfactory translations to readers, and at the same time fulfill the duty of intercultural communication (Xu, Chongxin, 1991).

\section{REFERENCES}

[1] Cao, Xueqin \& Gao, E. (1987). Hong Lou Meng. Changsha: Yue Lu Press.

[2] Cao, Xueqin \& Gao, E. (1973). The Story of the Stone. Translated by David Hawkes. London: Penguin Books Ltd.

[3] Eugene A. Nida \& Charles R. Taber. (1993). The Theory and Practice of Translation. Shanghai: Shanghai Foreign Language Education Press.

[4] Feng, Jianwen. (1993). Domestication and Preservation of the Exotic Flavor. Foreign Language Education, 1, 11-14.

[5] Hu, Cui'e. (2000). Rethinking on Domestication and Foreignization. Foreign Language and Translation, 1,45-48.

[6] Hu, Wenzhong. (1994). Culture and Communication. Beijing: Foreign Language Teaching and Research Press.

[7] Liu, Miqing. (1999).Contemporary Translation Theories. Beijing: China Translation \& Publishing Corporation.

[8] Mitchell, Margaret. (1979). Gone with the Wind. Translated by Fu Donghua. Hangzhou: Zhejiang People's Press.

[9] Merriam-Webster. (1967). Webster's Third New International Dictionary. Springfield: G \& C Merriam Company, Publishers.

[10] Schuttleworth \& Cowie. (1997). Dictionary of Translation Studies. Manchester: STJE Rome Publisher.

[11] Thackerary, William. (2000). Vanity Fair. Translated by Yanbi. Beijing: People's Literary Publishing House.

[12] Venuti, L. (1995). The Translator's Invisibility, London, New York: Routledge.

[13] Xu, Chongxin. (1991). Cultural Communication and Translation . Journal of Foreign Languages, 2, 29-34.

[14] Yang, Xianyi \& Gladays Yang (2010). A Dream of Red Mansions. Beijing: Foreign Languages Press.

[15] Ye, Zinan. (1991). On Westernized Translation. Chinese Translators Journal, 2, 15-18.

[16] Zhang, Baohong. (2001). Multiple Perspectives and Aesthetic Effects of Literary Translation. Foreign Language Education, 1, 61-67.

[17] Zhang, Jin. (1987). Fundamentals on Literary Translation. Kaifeng: He'nan University Press.

[18] Zhu, Jianping. (2002). Domestication and Foreignization: Shift of Researching Point. Journal of PLA University of Foreign Languages, 2, 78-82.

Fade Wang was born in Shandong, China in 1967. He received his M.A. in English language and literature from Shandong University, China in 1995. He is currently an associate professor in Foreign Language College, Huaiyin Institute of Technology, Jiangsu, China. His research interests include bilingual translation between English and Chinese, inter-cultural communication, and contrastive study between Eastern and Western cultures. 